\title{
Holocene atmospheric dust flux and peat accumulation in NW Russia
}

\author{
T. PAMPURA ${ }^{1 *}$, O. ZARUBINA $^{2}$, A. TSYGANOV $^{3}$, \\ AND M. MEILI ${ }^{4}$
}

${ }^{1}$ Inst. of Physicochemical and Biological Problems in Soil Science RAS, Pushchino, 142290, Russia

(*correspondence: pampura@mail.ru)

${ }^{2}$ Inst. of Geochemistry SB RAS, Irkutsk, 664033, Russia (zarub@igc.irk.ru)

${ }^{3}$ Biological Dept., Moscow State University, Moscow, 119991, Russia (andrey.tsyganov@bk.ru)

${ }^{4}$ Dept. of Environmental Science, Stockholm Univ., SE-106

91 Stockholm, Sweden (markus.meili@aces.su.se)

Changes in dust deposition and organic carbon (C) accumulation during the past 5500 yr were reconstructed using an ombrotrophic peat bog Staroselsky Mokh (Tver region, Russia). Peat samples were analysed for $\mathrm{Ti}$, Sc, rare earth elements (REE), $87 \mathrm{Sr} / 86 \mathrm{Sr}$ and $143 \mathrm{Nd} / 144 \mathrm{Nd}$. Further, bog water table depth (based on testate amoebae), degree of humification, loss on ignition, ash-free bulk density, and $\mathrm{C}$ content were determined. The age-depth curve was constructed using Bchron model and 14C (AMS) and 210Pb (CRS) dates. Dust fluxes calculated from Sc, Ti or REE concentrations all showed similar temporal trends. Based on the age-depth curve, three periods of high dust deposition (HDDP) were recorded: HDDP-1 (3400-3800 yr BP), HDDP2 (200-500 yr BP) and HDDP-3 (highest anthropogenic impact in XX century with maxima in 1930-1980s). The first two HDDPs coincide well with cold periods (mid-Holocene cooling and the Little Ice Age) according to a reconstruction of Holocene climate in the region [1]. Pollen analysis in the same peat [2] showed a simultaneous decline in forest cover, potentially facilitating production and dispersal of dust.

Interestingly, all three HDDPs coincide with high ash-free density and organic $\mathrm{C}$ accumulation rates. This indicates a more active peat growth since a decline in decomposition seems less likely considering a high degree of humification. A fertilising effect of dust may have stimulated growth due to elevated input of essential elements like $\mathrm{P}, \mathrm{K}$ (in HDDP-1) and $\mathrm{K}, \mathrm{Ca}, \mathrm{Mg}$ (in HDDP-2 and -3). The prominent negative $\mathrm{Eu}$ anomalies and lowest $\mathrm{La} / \mathrm{Yb}$ and $\mathrm{Sc} / \mathrm{Ti}$ ratios indicate a more intense weathering and a more coarse composition of dust during HDDPs. According to $\mathrm{Nd}-\mathrm{Sr}$ isotopes sources of dust changed over Holocene.

The study was supported by the Russian Foundation for Basic Research, project N 18-05-01115a.

[1] Seppä et al. (2004) Quaternary Research 22, 22-31.

[2] Novenko (2016), GEOS, Moscow, 228 p. 